2012s-02

\title{
Optimal Tariffs on Exhaustible Resources: The Case of Quantity Setting
}

\author{
Kenji Fujiwara, Ngo Van Long
}

\begin{tabular}{c}
\hline Série Scientifique \\
Scientific Series
\end{tabular}

\section{Montréal}

Janvier 2012

(C) 2012 Kenji Fujiwara,Ngo Van Long. Tous droits réservés. All rights reserved. Reproduction partielle permise avec citation du document source, incluant la notice $($ C.

Short sections may be quoted without explicit permission, if full credit, including (C) notice, is given to the source.
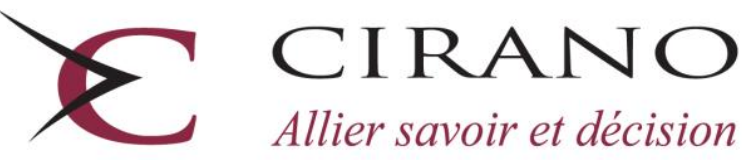

Allier savoir et décision

Centre interuniversitaire de recherche en analyse des organisations 


\section{CIRANO}

Le CIRANO est un organisme sans but lucratif constitué en vertu de la Loi des compagnies du Québec. Le financement de son infrastructure et de ses activités de recherche provient des cotisations de ses organisations-membres, d'une subvention d'infrastructure du Ministère du Développement économique et régional et de la Recherche, de même que des subventions et mandats obtenus par ses équipes de recherche.

CIRANO is a private non-profit organization incorporated under the Québec Companies Act. Its infrastructure and research activities are funded through fees paid by member organizations, an infrastructure grant from the Ministère du Développement économique et régional et de la Recherche, and grants and research mandates obtained by its research teams.

\section{Les partenaires du CIRANO}

\section{Partenaire majeur}

Ministère du Développement économique, de l'Innovation et de l'Exportation

\section{Partenaires corporatifs}

Autorité des marchés financiers

Banque de développement du Canada

Banque du Canada

Banque Laurentienne du Canada

Banque Nationale du Canada

Banque Royale du Canada

Banque Scotia

Bell Canada

BMO Groupe financier

Caisse de dépôt et placement du Québec

\section{CSST}

Fédération des caisses Desjardins du Québec

Financière Sun Life, Québec

Gaz Métro

Hydro-Québec

Industrie Canada

Investissements PSP

Ministère des Finances du Québec

Power Corporation du Canada

Rio Tinto Alcan

State Street Global Advisors

Transat A.T.

Ville de Montréal

\section{Partenaires universitaires}

École Polytechnique de Montréal

HEC Montréal

McGill University

Université Concordia

Université de Montréal

Université de Sherbrooke

Université du Québec

Université du Québec à Montréal

Université Laval

Le CIRANO collabore avec de nombreux centres et chaires de recherche universitaires dont on peut consulter la liste sur son site web.

Les cahiers de la série scientifique (CS) visent à rendre accessibles des résultats de recherche effectuée au CIRANO afin de susciter échanges et commentaires. Ces cahiers sont écrits dans le style des publications scientifiques. Les idées et les opinions émises sont sous l'unique responsabilité des auteurs et ne représentent pas nécessairement les positions du CIRANO ou de ses partenaires.

This paper presents research carried out at CIRANO and aims at encouraging discussion and comment. The observations and viewpoints expressed are the sole responsibility of the authors. They do not necessarily represent positions of CIRANO or its partners. 


\title{
Optimal Tariffs on Exhaustible Resources: The Case of Quantity Setting
}

\author{
Kenji Fujiwara ${ }^{*}$, Ngo Van Long ${ }^{\dagger}$
}

\begin{abstract}
Résumé / Abstract
On construit un modèle d'un jeu dynamique d'échange en ressource non-renouvelable sous l'hypothèse que le pays exportateur détermine la quantité au lieu du prix. L'objectif est de comparer l'équilibre de Nash avec les équilibres de Stackelberg. Dans un premier temps, c'est le pays importateur qui est le leader. Dans un deuxième temps, le pays exportateur assume le leadership. On démontre numériquement que, par rapport à l'équilibre de Nash, le niveau de bien-être des deux pays est plus élevé sous l'équilibre de Stackelberg dans le cas où l'importateur est le leader. Dans le cas où le pays exportateur est le leader, le niveau de bienêtre du pays importateur est moins élevé que celui de l'équilibre de Nash. Le bien-être du monde entier dans le cas du leadership du pays importateur est plus élevé que dans le cas opposé.
\end{abstract}

Mots clés : jeu dynamique, ressources non-renouvelables, leadership de Stackelberg.

Constructing a dynamic game model of trade of an exhaustible resource, this paper compares feedback Nash and Stackelberg equilibria when the exporting country sets quantity rather than price. We consider two different leadership scenarios: leadership by the importing country, and leadership by the exporting country. We numerically show that as compared to the Nash equilibrium, both countries are better off if the importing country is a leader, but that the follower is worse off if the exporting country is a leader. Consequently, the world welfare is highest under the importing country's leadership and lowest under the exporting country's leadership.

Keywords: dynamic game, exhaustible resource, Stackelberg leadership.

Codes JEL: C73, L72, Q34, F18

\footnotetext{
${ }^{*}$ Department of Economics, Kwansai Gakuin University, Japan. Email kenjifujiwara @kwanse.ac.jp

${ }^{\dagger}$ Department of Economics, McGill University, 855 Sherbrooke St West, Montreal, H3A 2T7, Canada. Email: ngo.long@mcgill.ca
} 


\section{Introduction}

The world markets for gas and oils consist mainly of a small number of large sellers and buyers. For instance, the U.S. Energy Information Administration reports that the major energy exporters concentrate on the Middle East and Russia whereas the United States, Japan and China have a substantial share in the imports. ${ }^{1}$ These data suggest that bilateral monopoly roughly prevails in the oil market in which both parties exercise market power. What are the implications of market power for welfare of importing and exporting countries, and the world?

There is a large literature that attempts to answer this question by using a dynamic game. Newbery (1976) and Kemp and Long (1980) are among the earliest contributions, showing that the optimal tariff is time inconsistent in an open-loop Stackelberg equilibrium. ${ }^{2}$ In order to overcome this difficulty, Karp and Newbery $(1991,1992)$ consider a feedback (Markovian) model in which importing countries play a dynamic game with perfectly competitive exporters. Karp and Newbery (1991) compare two situations, in one of which the importing countries are the first movers in each period while in the other the competitive exporters choose their outputs before the importing countries set their tariff rates. They numerically demonstrate that being the firstmover can be disadvantageous. In a related paper, Karp and Newbery (1992) make a welfare comparison between free trade and the Markov perfect Nash equilibrium.

While Karp and Newbery $(1991,1992)$ assume perfect competition among suppliers, Wirl (1994) considers the bilateral monopoly case, when both the importing and exporting countries have market power, and computes a feedback Nash equilibrium. His novel result is that resource extraction is more conservative than the globally efficient level, but that along the equilibrium

\footnotetext{
${ }^{1}$ The latest data are available at http://www.eia.gov/.

${ }^{2}$ The time consistency issue is further studied by Karp (1984) who assumes that production cost depends on the resource stock. Newbery (1981) does not deal with the optimal tariff issues, but points another type of time inconsistency when a cartel is the open-loop Stackelberg leader and a fringe of competitive producers acts as the followers.
} 
path, the remaining stock converges to the efficient steady state level. ${ }^{3}$ His model has been extended in several ways. Chou and Long (2009), maintaining the assumption of Nash behavior, extend the model to accommodate many importers and compare welfare in free trade and the Nash equilibrium. Tahvonen (1996) and Rubio and Escriche (2001) turn attention to Stackelberg games. Both papers show that outcome of the Nash equilibrium is identical to that of the Stackelberg equilibrium where the exporting country leads. $^{4}$

This paper is also in line with this bilateral monopoly literature, but our model and purpose are quite different. First, we consider the case where the seller chooses quantity whereas all of the above papers assume pricesetting behavior. Given the fact that recent price fluctuations of oil are partially caused by quantity control by the resource-rich countries, our quantitysetting formulation seems more plausible. Second, we compare welfare of each country and the world in the Nash equilibrium and the two Stackelberg equilibria where the leadership role is taken by the importer and the exporter, respectively. Third and most importantly, we derive feedback Stackelberg equilibria which are conceptually different from Tahvonen (1996) and Rubio and Escriche (2001). Roughly speaking, they assume that the leader moves first in each period, but does not necessarily try to improve upon its Nash equilibrium payoff stream. Such a solution may be called a stagewise Stackelberg equilibrium. In contrast, since we suppose that the leader determines a Markovian rule over the entire horizon of the game, a solution concept that may be called a global Stackelberg equilibrium. ${ }^{5}$ With these differences, we establish that (i) as compared to the Nash equilibrium, both the exporting country and the (strategically-behaving) importing country are better off if

\footnotetext{
${ }^{3}$ In the steady state, a positive resource stock remains in the ground even though extraction is costless. This is because a Pigouvian tax that corrects stock-pollution externalities chokes off the demand.

${ }^{4}$ While Wirl (1994) assumes costless extraction, Tahvonen postulates a quadratic extraction cost function, and the other two papers assume a stock-dependent cost.

${ }^{5}$ This concept is discussed in Dockner et al. (2000), Basar and Olsder (1995), Mehlmann (1988), and Long (2010).
} 
the importing country leads, (ii) the importing country becomes worse off if the exporting country leads, and (iii) the world welfare is highest under the importing country's leadership and lowest under the exporting country's leadership. Therefore, the important implication derived from our findings is that the importing country should have a leadership over the exporting country.

These findings are in sharp contrast to the results of Tahvonen (1996) and Rubio and Escriche (2001) that the exporting country's welfare under its leadership is the same as in the Nash equilibrium. They are also in sharp contrast to the price-setting model of Fujiwara and Long (2011) where the world welfare is highest in the Nash equilibrium. ${ }^{6}$

This paper is organized as follows. Section 2 presents a model. Section 3 derives the feedback Nash equilibrium. Sections 4 characterizes the feedback Stackelberg equilibrium in which the importing country is the leader. Section 5 , on the other hand, turns to the feedback Stackelberg equilibrium in which the exporting country leads. Section 6 presents numerical results. Section 7 concludes.

\section{The Model}

This section presents the model. There are three countries labeled Home, Foreign, and ROW (the rest of the world). A Foreign monopolistic firm exports a good denoted by $y$ to Home and ROW exclusively. ${ }^{7}$ This good comes from the extraction of an exhaustible resource.

Due to geological factors, it is commonly observed that marginal extraction cost increases as the remaining stock of resource decreases. ${ }^{8}$ This feature

\footnotetext{
${ }^{6}$ Fujiwara and Long (2011) assume that the exporting country chooses prices, as in the cited papers.

${ }^{7}$ The good is not consumed in Foreign, and the market of Home and ROW is assumed to be integrated and hence the Foreign firm does not supply to each country separately.

${ }^{8}$ In a recent exposition of the state of the oil market, Smith (2009, p. 147) points out that most of the oil in any given deposit will never be produced, and therefore does not count as proved reserves, because it would be too costly to effect complete recovery." This indicates that the "exhaustion" of a deposit should be interpreted as an "abandonment"
} 
has been taken into account by various authors. Our formulation of extraction cost is closest to that of Karp (1984).

Let $\bar{X}$ be the initial size of the deposit and $X(t)$ be the stock of resource that remains at time $t$, and define $S(t)=\bar{X}-X(t) \geq 0$. Then, marginal extraction cost is increasing in $S$. Letting $y(t)$ denote the extraction at time $t$, the cost of extracting $y(t)$ is assumed to be $C=\left[c_{A}+c S(t)\right] y(t)$, where $c_{A} \geq 0$ and $c>0$. In what follows, we set $c_{A}=0$ for simplicity. Our results are not qualitatively affected even if $c_{A}$ is positive.

Denote by $a$ the maximum price that consumers would be willing to pay for the first unit of resource consumed at any $t$, which is called the choke price. It is clear if marginal cost of extraction, $c S(t)$, is higher than the choke price, it is socially inefficient to extract the resource. Therefore, extraction must stop as soon as $S(t)$ reaches the critical level $\bar{S}=a / c$ (if $\bar{X}$ is sufficiently large so that $S$ can reach $\bar{S}$ before exhaustion). In what follows, we assume that $\bar{X}$ is large enough so that the resource stock is abandoned before exhaustion. ${ }^{9}$ The utility function of the two importing countries is specified by ${ }^{10}$

$$
\begin{aligned}
u^{H} & =a q_{1}^{H}-\frac{\left(q_{1}^{H}\right)^{2}}{2 b}+q_{2}^{H} \\
u^{R O W} & =a q_{1}^{R O W}-\frac{\left(q_{1}^{R O W}\right)^{2}}{2(1-b)}+q_{2}^{R O W}, \quad a>0,
\end{aligned}
$$

where $u^{i}, i=H, R O W$ is utility of Home and ROW, and $q_{1}^{i}$ and $q_{2}^{i}$ are consumption of the imported good and numeraire good, respectively. The parameter $b \in(0,1)$ represents the share of the Home demand in the world demand if there is no tariff. Assuming that the Home government imposes a specific tariff on the import of Good 1 and that ROW observes laissezfaire, utility maximization under the budget constraint yields the demand functions

$$
q_{1}^{H}=b(a-p-\tau), \quad q_{1}^{R O W}=(1-b)(a-p),
$$

\footnotetext{
of the deposit after the profitable part has been exploited.

${ }^{9}$ Karp (1984) also focuses on this case.

${ }^{10}$ In what follows, the time argument $t$ is suppressed unless any confusion arises.
} 
where $p$ is the world price of Good 1 and $\tau$ is the tariff imposed by Home. Letting $y$ be the total supply of the Foreign firm, the market-clearing condition is

$$
b(a-p-\tau)+(1-b)(a-p)=a-p-b \tau=y,
$$

from which the inverse demand function is defined by $p=a-y-b \tau$. Substituting this into (2) and (1), and considering that Home's welfare $W$ consists of consumer surplus and tariff revenue, we obtain

$$
\begin{aligned}
W & =a q_{1}^{H}-\frac{\left(q_{1}^{H}\right)^{2}}{2 b}-(p+\tau) q_{1}^{H}+\tau q_{1}^{H} \\
& =\frac{b[y+(1+b) \tau][y-(1-b) \tau]}{2} \\
& =\frac{b\left[y^{2}+2 b \tau y-\left(1-b^{2}\right) \tau^{2}\right]}{2} .
\end{aligned}
$$

On the other hand, the Foreign firm's profit $\pi$ is

$$
\pi=(a-b \tau-c S-y) y
$$

Home and Foreign strategically choose a time profile of $\tau$ and $y$ by taking into account the resource dynamics in an infinite time horizon. Thus, the present model takes the form of the following dynamic game:

$$
\begin{array}{ll}
\max _{\tau} & \int_{0}^{\infty} e^{-r t} W d t \\
\max _{y} & \int_{0}^{\infty} e^{-r t} \pi d t \\
\text { s.t. } & \dot{S}=y, \quad S(0)=S_{0}>0, \quad \lim _{t \rightarrow \infty} S(t) \leq \frac{a}{c},
\end{array}
$$

where $r>0$ is a common rate of discount. The subsequent sections find the Nash and Stackelberg solutions under linear feedback (Markovian) strategies.

\section{Feedback Nash Equilibrium}

This section considers a feedback Nash equilibrium of the above game. For this purpose, let us define each player's Hamilton-Jacobi-Bellman (HJB) 
equation. By the assumption of simultaneous moves, Home does not observe the firm's output $y(t)$ when it makes the tariff decision $\tau(t)$, and the Foreign firm makes its output decision without knowing the tariff rate $\tau(t)$. Assume the Home government thinks that the Foreign firm has the output strategy $y=\phi(S)$ while the Foreign firms thinks that the Home country has the tariff strategy $\tau=\psi(S)$. Then, the two HJB equations are

$$
\begin{aligned}
r V(S) & =\max _{\tau}\left\{\frac{b\left\{[\phi(S)]^{2}+2 b \tau \phi(S)-\left(1-b^{2}\right) \tau^{2}\right\}}{2}+V_{S}(S) \phi(S)\right\} \\
r V^{*}(S) & =\max _{y}\left\{[a-b \psi(S)-c S-y] y+V_{S}^{*}(S) y\right\},
\end{aligned}
$$

where $V(S)$ and $V^{*}(S)$ are the value function of Home and Foreign. The firstorder conditions for maximizing the right-hand side of the HJB equations give

$$
\begin{aligned}
b \phi(S)-\left(1-b^{2}\right) \tau & =0 \\
a-b \psi(S)-c S-2 y+V_{S}^{*}(S) & =0 .
\end{aligned}
$$

In equilibrium, what each player thinks about the other's strategy is correct and thus we have

$$
\begin{aligned}
\tau & =\psi(S)=\frac{b\left(a-c S+V_{S}^{*}\right)}{2-b^{2}} \\
y & =\phi(S)=\frac{\left(1-b^{2}\right)\left(a-c S+V_{S}^{*}\right)}{2-b^{2}} . .
\end{aligned}
$$

Substituting these into the Foreign HJB equation, we obtain

$$
r V^{*}(S)=[\phi(S)]^{2}=\left[\frac{\left(1-b^{2}\right)\left(a-c S+V_{S}^{*}\right)}{2-b^{2}}\right]^{2} .
$$

Let us guess that the value function is quadratic in $S$ because of our restriction of linear strategies. Then, the HJB equation of Foreign becomes

$$
r\left(\frac{A^{*}}{2} S^{2}+B^{*} S+C^{*}\right)=\left\{\frac{\left(1-b^{2}\right)\left[\left(A^{*}-c\right) S+B^{*}+a\right]}{\left(2-b^{2}\right)}\right\}^{2} .
$$

where $A^{*}, B^{*}$ and $C^{*}$ are to be determined. Equating the coefficients of the terms $S^{2}, S$, and the constant terms on both sides of the equation, we get

$$
A^{*}=\frac{4 c\left(1-b^{2}\right)^{2}+r\left(2-b^{2}\right)^{2}-\left(2-b^{2}\right) \sqrt{\Delta}}{4\left(1-b^{2}\right)^{2}}
$$




$$
\begin{aligned}
B^{*} & =\frac{\left[r\left(2-b^{2}\right)-\sqrt{\Delta}\right] a}{r\left(2-b^{2}\right)+\sqrt{\Delta}} \\
C^{*} & =r\left[\frac{2\left(1-b^{2}\right) a}{r\left(2-b^{2}\right)+\sqrt{\Delta}}\right]^{2} \\
\Delta & \equiv 8 c r\left(1-b^{2}\right)^{2}+r^{2}\left(2-b^{2}\right)^{2}>0 .
\end{aligned}
$$

In a similar way, we can obtain the coefficients of Home's value function $V(S)=A S^{2} / 2+B S+C$ as follows.

$$
\begin{aligned}
A & =\frac{b\left[r\left(2-b^{2}\right)-\sqrt{\Delta}\right]^{2}}{8\left(1-b^{2}\right)^{2}\left(-r b^{2}+\sqrt{\Delta}\right)} \\
B & =\frac{r b\left[r\left(2-b^{2}\right)-\sqrt{\Delta}\right] a}{\left(-r b^{2}+\sqrt{\Delta}\right)\left[r\left(2-b^{2}\right)+\sqrt{\Delta}\right]} \\
C & =\frac{b}{-r b^{2}+\sqrt{\Delta}}\left[\frac{2 r\left(1-b^{2}\right) a}{r\left(2-b^{2}\right)+\sqrt{\Delta}}\right]^{2} .
\end{aligned}
$$

Accordingly, in the Markov perfect Nash equilibrium (hereafter, MPNE), the tariff strategy and the output strategy are

$$
\begin{aligned}
\tau & =\psi(S)=\alpha_{N} S+\beta_{N} \\
& =\frac{b\left[r\left(2-b^{2}\right)-\sqrt{\Delta}\right]}{4\left(1-b^{2}\right)^{2}} S-\frac{b\left[r\left(2-b^{2}\right)-\sqrt{\Delta}\right] a}{4 c\left(1-b^{2}\right)^{2}} \\
y & =\phi(S)=\alpha_{N}^{*} S+\beta_{N}^{*} \\
& =\frac{r\left(2-b^{2}\right)-\sqrt{\Delta}}{4\left(1-b^{2}\right)} S-\frac{\left[r\left(2-b^{2}\right)-\sqrt{\Delta}\right] a}{4 c\left(1-b^{2}\right)} .
\end{aligned}
$$

Using these results, we can arrive at:

Proposition 1. There exists a unique feedback Nash equilibrium in linear strategies where both the equilibrium tariff and output converge to zero.

Proof. The resource dynamics in linear strategies is

$$
\dot{S}=y=\alpha_{N}^{*} S+\beta_{N}^{*}=\alpha_{N}^{*}\left(S+\frac{\beta_{N}^{*}}{\alpha_{N}^{*}}\right)=\alpha_{N}^{*}\left(S-\frac{a}{c}\right) .
$$

Thus, as $S(t)$ approaches the steady state $S_{\infty}=a / c$, we have $y \rightarrow 0$ and consequently $\tau \rightarrow 0$ because $\tau=b y /\left(1-b^{2}\right)$. $\|$ 


\section{Feedback Stackelberg Equilibrium with Im- porter's Leadership}

In this section and the next one we turn to two Stackelberg equilibria. This section considers the case where Home is the leader. In order to solve the game backward, we begin by examining Foreign's behavior. The Foreign firm anticipates that the leader chooses a strategy $\tau(S)=\alpha S+\beta$. Then, the Foreign firm's HJB equation is

$$
r V^{*}(S)=\max _{y}\left\{\left[a-b(\alpha S+\beta)-c S-y+V_{S}^{*}(S)\right] y\right\} .
$$

Guessing $V^{*}(S)=A^{*} S^{2} / 2+B^{*} S+C^{*}$, the first-order condition for maximizing the right-hand side gives the follower's reaction function:

$$
y(S)=\frac{\left(A^{*}-b \alpha-c\right) S+B^{*}+a-b \beta}{2} .
$$

Substituting this into the HJB equation, we have

$$
r V^{*}(S)=[y(S)]^{2}
$$

Applying this equation to the above specification of the value function, the three coefficients will be

$$
\begin{aligned}
A^{*} & =b \alpha+c+r-\sqrt{\Gamma} \\
B^{*} & =\frac{(r-\sqrt{\Gamma})(a-b \beta)}{r+\sqrt{\Gamma}} \\
C^{*} & =\frac{1}{r}\left[\frac{(r-\sqrt{\Gamma})(a-b \beta)}{2(b \alpha+c)}\right]^{2} \\
\Gamma & \equiv r(2 b \alpha+2 c+r)>0 .
\end{aligned}
$$

Substituting these into (16), the Foreign firm's strategy is

$$
y(S)=\alpha^{*} S+\beta^{*}=\frac{r-\sqrt{\Gamma}}{2} S-\frac{(r-\sqrt{\Gamma})(a-b \beta)}{2(b \alpha+c)} .
$$

Let us turn to the solving the leader's problem, which involves a few auxiliary steps. First, considering that the resource dynamics is expressed by $\dot{S}=$ 
$\alpha^{*} S+\beta^{*}$, the solution is

$$
S(t)=e^{\alpha^{*} t}\left(S_{0}+\frac{\beta^{*}}{\alpha^{*}}\right)-\frac{\beta^{*}}{\alpha^{*}} .
$$

Second, under the linear strategies $\tau=\alpha S+\beta$ and $y=\alpha^{*} S+\beta^{*}$, the Home welfare flow at $t$ with the resource stock $S$ is

$$
\begin{aligned}
\frac{2 W}{b}= & \left(\alpha^{*} S+\beta^{*}\right)^{2}+2 b(\alpha S+\beta)\left(\alpha^{*} S+\beta^{*}\right)-\left(1-b^{2}\right)(\alpha S+\beta) \\
= & {\left[\alpha^{* 2}+2 b \alpha \alpha^{*}-\left(1-b^{2}\right) \alpha^{2}\right] S^{2}+2\left[\alpha^{*} \beta^{*}+b\left(\alpha \beta^{*}+\alpha^{*} \beta\right)-\left(1-b^{2}\right) \alpha \beta\right] S } \\
& +\beta^{* 2}+2 b \beta \beta^{*}-\left(1-b^{2}\right) \beta^{2} \\
= & \frac{-2\left(1-b^{2}\right) \alpha^{2}+r(3 b \alpha+c+r)-(2 b \alpha+r) \sqrt{\Gamma}}{2} e^{(r-\sqrt{\Gamma}) t}\left(S_{0}+\frac{\beta^{*}}{\alpha^{*}}\right)^{2} \\
& -\frac{(\alpha a+\beta c)\left[2\left(1-b^{2}\right) \alpha-b(r-\sqrt{\Gamma})\right]}{b \alpha+c} e^{\frac{r-\sqrt{\Gamma}}{2} t}\left(S_{0}+\frac{\beta^{*}}{\alpha^{*}}\right) \\
& -\left(1-b^{2}\right)\left(\frac{\alpha a+\beta c}{b \alpha+c}\right)^{2},
\end{aligned}
$$

where the last equation uses (21).

Third, taking the integral of the discounted sum of welfare, we have

$$
\begin{aligned}
\int_{0}^{\infty} e^{-r t} \frac{2 W}{b}= & \frac{-2\left(1-b^{2}\right) \alpha^{2}+r(3 b \alpha+c+r)-(2 b \alpha+r) \sqrt{\Gamma}}{2 \sqrt{\Gamma}}\left(S_{0}+\frac{\beta^{*}}{\alpha^{*}}\right)^{2} \\
& -\frac{2\left[2\left(1-b^{2}\right) \alpha-b(r-\sqrt{\Gamma})(\alpha a+\beta c)\right]}{(r+\sqrt{\Gamma})(b \alpha+c)}\left(S_{0}+\frac{\beta^{*}}{\alpha^{*}}\right) \\
& -\frac{1-b^{2}}{r}\left(\frac{\alpha a+\beta c}{b \alpha+c}\right)^{2}
\end{aligned}
$$

which is to be maximized by Home by controlling $\alpha$ and $\beta$. Since this is just a static maximization problem, the optimal value of $\alpha$ and $\beta$ is in principle obtained with calculus only. However, one can see that the solutions of $\alpha$ and $\beta$ obtained through this method would depend on $S_{0}$, which implies that such solutions are time-inconsistent. In order to overcome this difficulty, we impose a time consistency condition: the restriction that $\alpha a+\beta c=0$ so that the second and the third terms in (22) vanish and the first-order condition becomes independent of $S_{0}$. 
Under this restriction, the Foreign output is, from (20),

$$
y(S)=\alpha^{*} S+\beta^{*}=\frac{r-\sqrt{\Gamma}}{2}\left(S-\frac{a}{c}\right)
$$

and Foreign welfare is, from (22),

$$
V^{*}(S)=\frac{1}{r}\left[\frac{r-\sqrt{\Gamma}}{2}\left(S-\frac{a}{c}\right)\right]^{2} .
$$

With the time consistency condition, our maximization problem amounts to

$$
\max _{\alpha} \frac{-2\left(1-b^{2}\right) \alpha^{2}+r(3 b \alpha+c+r)-(2 b \alpha+r) \sqrt{\Gamma}}{2 \sqrt{\Gamma}}\left(S_{0}-\frac{a}{c}\right)^{2} .
$$

The first-order condition for this maximization problem is

$2 b(2 b \alpha+2 c+r) \sqrt{r(2 b \alpha+2 c+r)}=-2\left(1-b^{2}\right) \alpha(3 b \alpha+4 c+2 r)+r b(3 b \alpha+5 c+2 r)$,

which is equivalent to

$$
\begin{aligned}
\frac{4 r^{\frac{1}{2}} b^{2} \theta^{\frac{3}{2}}}{1-b^{2}} & =-3 \theta^{2}+\theta\left(\frac{3 r b^{2}}{1-b^{2}}+4 c+2 r\right)+\left[\frac{r b^{2}(4 c+r)}{1-b^{2}}+(2 c+r)^{2}\right] \\
& \equiv-3 \theta^{2}+\eta \theta+\mu,
\end{aligned}
$$

by transforming the variables such that $\theta=2 b \alpha+2 c+r$. In the present case, we can prove a result that is parallel to Proposition 1:

Proposition 2. Suppose that the importing country is a leader. Then, there exists a unique global Stackelberg equilibrium in linear strategies where both the equilibrium tariff and output converge to zero.

Proof. Under the time consistency condition, we have

$$
\tau(S)=\alpha S+\beta=\alpha S-\frac{\alpha a}{c}=\alpha\left(S-\frac{a}{c}\right) .
$$

Thus, the steady state in which $S=a / c$ involves $\tau(a / c)=0$, and $y(a / c)=0$ from (23). ॥ 


\section{$5 \quad$ Feedback Stackelberg Equilibrium with Ex- porter's Leadership}

Finally, this section deals with the case in which the Foreign firm is a leader. Supposing that the leader's strategy is $y(S)=\alpha^{*} S+\beta^{*}$, Home's HJB equation is

$r V(S)=\max _{\tau}\left\{\frac{b\left[\left(\alpha^{*} S+\beta^{*}\right)^{2}+2 b \tau\left(\alpha^{*} S+\beta^{*}\right)-\left(1-b^{2}\right) \tau^{2}\right]}{2}+V_{S}(S)\left(\alpha^{*} S+\beta^{*}\right)\right\}$

The first-order condition for maximizing the right-hand side yields

$$
\tau(S)=\frac{b\left(\alpha^{*} S+\beta^{*}\right)}{1-b^{2}} .
$$

Substituting this into the definition of the Foreign firm's profit, we have

$$
\pi=\left[a-\frac{b^{2}\left(\alpha^{*} S+\beta^{*}\right)}{1-b^{2}}-c S-\alpha^{*} S-\beta^{*}\right]\left(\alpha^{*} S+\beta^{*}\right)
$$

Noting that $S$ depends on $\alpha^{*}$ and $\beta^{*}$ in such a way that

$$
S(t)=e^{\alpha^{*} t}\left(S_{0}+\frac{\beta^{*}}{\alpha^{*}}\right)-\frac{\beta^{*}}{\alpha^{*}}
$$

the above profit is rewritten further:

$$
\begin{aligned}
\left(1-b^{2}\right) \pi= & -\alpha^{*}\left[\alpha^{*}+\left(1-b^{2}\right) c\right] S^{2}+\left[-2 \alpha^{*} \beta^{*}+\left(1-b^{2}\right)\left(\alpha^{*} a-\beta^{*} c\right)\right] S \\
& -\beta^{*}\left[\beta^{*}-\left(1-b^{2}\right) a\right] \\
= & -\alpha^{*}\left[\alpha^{*}+\left(1-b^{2}\right) c\right] e^{2 \alpha^{*} t}\left(S_{0}+\frac{\beta^{*}}{\alpha^{*}}\right)^{2}+\left(1-b^{2}\right)\left(\alpha^{*} a+\beta^{*} c\right) e^{\alpha^{*} t}\left(S_{0}+\frac{\beta^{*}}{\alpha^{*}}\right)
\end{aligned}
$$

Taking the integral from 0 to $\infty$, the Foreign firm's objective function becomes

$\int_{0}^{\infty} e^{-r t}\left(1-b^{2}\right) \pi d t=\frac{-\alpha^{*}\left[\alpha^{*}+\left(1-b^{2}\right) c\right]}{r-2 \alpha^{*}}\left(S_{0}+\frac{\beta^{*}}{\alpha^{*}}\right)^{2}+\frac{\left(1-b^{2}\right)\left(\alpha^{*} a+\beta^{*} c\right)}{r-\alpha^{*}}\left(S_{0}+\frac{\beta^{*}}{\alpha^{*}}\right)$,

which is maximized by Foreign that chooses $\alpha^{*}$ and $\beta^{*}$.

In principle, we can find the equilibrium strategy of the leader by seeking $\alpha^{*}$ and $\beta^{*}$ which maximize this function. However, such solutions can be 
time-inconsistent for the same reason as in the preceding section. Therefore, we must impose once again the time consistency condition: $\alpha^{*} a+\beta^{*} c=0$. Under it, the welfare of the leader becomes

$$
\frac{-\alpha^{*}\left[\alpha^{*}+\left(1-b^{2}\right) c\right]}{\left(r-2 \alpha^{*}\right)\left(1-b^{2}\right)}\left(S_{0}-\frac{a}{c}\right)
$$

which is to be maximized with respect to $\alpha^{*}$. The associated first-order condition is

$$
\frac{2 \alpha^{*}-2 r \alpha^{*}-r\left(1-b^{2}\right) c}{\left(r-2 \alpha^{*}\right)^{2}}=0
$$

which yields

$$
\begin{aligned}
\alpha^{*} & =\frac{r-\sqrt{\Phi}}{2}<0 \\
\Phi & \equiv 2 r c\left(1-b^{2}\right)+r^{2}>0 .
\end{aligned}
$$

Moreover, using (27), we can derive the coefficients of the follower's value function $V(S)=A S^{2} / 2+B S+C$ as follows.

$$
\begin{aligned}
A & =\frac{b \alpha^{* 2}}{\left(1-b^{2}\right)\left(r-2 \alpha^{*}\right)} \\
B & =\frac{b \alpha^{*} \beta *}{\left(1-b^{2}\right)\left(r-2 \alpha^{*}\right)} \\
C^{*} & =\frac{b \beta^{* 2}}{2\left(1-b^{2}\right)\left(r-2 \alpha^{*}\right)} .
\end{aligned}
$$

Based on these results, we can prove a result that is parallel to Propositions 1 and 2:

Proposition 3. Suppose that the exporting country is a leader. Then, there exists a unique global Stackelberg equilibrium in linear strategies where both the equilibrium tariff and output converge to zero.

Proof. Under the time consistency condition, we have

$$
y(S)=\alpha^{*} S+\beta^{*}=\alpha\left(S-\frac{a}{c}\right), \quad \tau(S)=\frac{b y(S)}{1-b^{2}} .
$$

Hence, in the steady state such that $S=a / c$, both $y(S)$ and $\tau(S)$ converges to zero. II 


\section{$6 \quad$ Welfare Implications}

Having derived three equilibria, this section examines welfare implications of these equilibria. In the analysis, we must resort to numerical examples since the equilibrium condition in each equilibrium involves a complicated polynomial. In what follows, we assume $S_{0}=0, r=0.1, c=1$ and $b^{2}=0.5$ $(b \approx 0.71){ }^{11}$

\section{(Tables 1 and 2 around here)}

Tables 1 and 2 report a comparison among the equilibrium strategies. When Home (the importing country) is a leader, it chooses a lower initial tariff than in the Nash equilibrium. This is because the Home government is motivated to counter the tendency of Foreign to be conservationist. ${ }^{12}$ In response to this strategy of Home, Foreign (the exporting country) naturally increases production. If, on the other hand, Foreign is a leader, it chooses a lower output earlier on to seek a high price and large rent. Observing this strategy choice of Foreign, Home retaliates by lowering a tariff for shifting the Foreign rent. These findings are well consistent with the outcomes in static games. ${ }^{13}$

\section{(Figures 1 and 2 around here) \\ (Table 3 around here)}

Table 3 summarizes the welfare comparisons among equilibria. Not surprisingly, the leader improves its welfare as compared to the Nash equilibrium, which comes from the definition of the Stackelberg equilibria. In contrast, the effect on the follower's welfare is different between the two Stackelberg equilbiria. If Home leads, welfare of Foreign as well as Home improves, i.e., Home's leadership entails a Pareto improvement from the Nash

\footnotetext{
${ }^{11}$ The detailed derivations of the tables in this paper are available from the authors upon request.

${ }^{12}$ Recall Solow's quiz that the resource monopolist is the conservationist's best friend.

${ }^{13}$ Figures 1 and 2 depict the two Stackelberg equilibria in a static setting. In the figures, points $N, H$ and $F$ refer to the Nash equilibrium, the Stackelberg equilibrium with Home's leadership and the Stackelberg equilibrium with Foreign's leadership, respectively.
} 
equilibrium. However, if Foreign leads, Home (the follower) becomes worse off than in the Nash equilibrium. These welfare changes are also confirmed in Figures 1 and 2 in which static games are assumed.

The third column in Table 3 shows the welfare levels of ROW. It reveals that the presence of leaderships has a detrimental effect on ROW and that its welfare is lowest when Foreign is a leader. The last column provides the welfare of the world, defined as the sum of the three countries' welfare. We can easily see that the world welfare is highest when Home is a leader. This is because, as mentioned just above, this case yields a Pareto improvement from the Nash equilibrium. On the other hand, when Foreign is a leader, the world welfare is lowest. The reason is that Foreign chooses a much smaller output than in the Nash case, which reduces consumer surplus of the two importing countries. As a result, the absolute value of the fall in welfare of Home and ROW exceeds the welfare gain of Foreign, which leads to the lowest welfare of the world.

\section{(Figure 3 around here)}

Finally, we draw diagrams that depict a dynamic path of welfare of Home and Foreign. Figure 3 consists of three panels. The top panel gives the time path of Home welfare under the three different scenarios. The middle panel gives the corresponding time paths of Foreign welfare, and the bottom one gives time paths of the world welfare. The top panel tells us that Home welfare is highest when it is a leader until a certain time, but after that time it is the highest when Foreign is a leader. ${ }^{14}$ The same observation cannot be made concerning the Foreign welfare: it is always highest when the Foreign firm assumes the leadership. As to the world welfare, the ranking reversal similar to Home welfare is found.

\footnotetext{
${ }^{14}$ However, note that the stock levels are not the same at the point where the two paths intersect each other.
} 


\section{Concluding Remarks}

We have explored feedback Stackelberg equilibria in a two-(strategic) country dynamic game model of an exhaustible resource. Unlike the existing literature that employs a stagewise Stackelberg solution, we have paid attention to the hierarchical Stackelberg equilibria. Despite the above contributions, we have left much unexplored. In particular, we have restricted attention to linear strategies. However, Shimomura and Xie (2008) have provided an example of renewable resource exploitation in which there exist nonlinear feedback strategies that are superior to linear strategies. ${ }^{15}$ Tackling this problem in the context of exhaustible resource markets is part of our future research agenda.

\section{References}

[1] Basar, T. and G. Olsder (1995), Dynamic Noncooperative Game Theory, San Diego, Academic Press.

[2] Chou, S. and N. V. Long (2009), "Optimal Tariff on Exhaustible Resource in the Presence of Cartel Behavior," Asia-Pacific Journal of Accounting and Economics, 16: 239-254.

[3] Dockner, E., S. Jorgensen, N. V. Long and G. Sorger (2002), Differential Games in Economics and Management Science, Cambridge, Cambridge University Press.

[4] Fujiwara, K. and N. V. Long (2011), "Welfare Implications of Leadership in a Resource Market under Bilateral Monopoly," Dynamic Games and Applications, 1: 479-497.

[5] Karp L. (1984), "Optimality and Consistency in a Differential Game of Non-Renewable Resources," Journal of Economics Dynamics and Control, 8: 73-98.

\footnotetext{
${ }^{15}$ For further issues relating to Stackelberg leadership with a renewable resource, see Long and Sorger (2010).
} 
[6] Karp, L. and D. Newbery (1991), "Optimal Tariffs on Exhaustible Resources," Journal of International Economics, 30: 285-299.

[7] Karp, L., and D. Newbery (1992), "Dynamically Consistent Oil Import Tariffs," Canadian Journal of Economics, 25: 1-21.

[8] Kemp, M. C. and N. V. Long (1980), "Optimal Tariffs on Exhaustible Resources," in Kemp, M. C. and N. V. Long (eds.), Exhaustible Resources, Optimality, and Trade, Amsterdam: North Holland, 183-186.

[9] Long, N. V. (2010), A Survey of Dynamic Games in Economics, Singapore, World Scientific Publishing Co.

[10] Long, N. V. and G. Sorger (2010), "A Dynamic Principal-Agent Problem as a Feedback Stackelberg Differential Game," Central European Journal of Operations Research, 18: 491-509.

[11] Mehlmann, A. (1988), Applied Differential Games, New York, Kluwer Academic Publishers.

[12] Newbery, D. (1976), "A Paradox in Tax Theory: Optimal Tariffs on Exhaustible Resources" typescript, Cambridge University.

[13] Newbery, D. (1981), "Oil Prices, Cartels, and Dynamic Inconsistency," Economic Journal, 91: 617-646.

[14] Rubio, S. and L. Escriche (2001), "Strategic Pigouvian Taxation, Stock Externalities and Polluting Non-renewable Resources," Journal of Public Economics, 79: 297-313.

[15] Shimomura, K. and D. Xie (2008), "Advances on Stackelberg Open-Loop and Feedback Strategies," International Journal of Economic Theory, 4: 115-133.

[16] Smith, J. L., (2009), "World Oil: Market or Mayhem?" Journal of Economic Perspective, Vol. 23(3): 145-164. 
[17] Tahvonen, O. (1996), "Trade with Polluting Non-Renewable Resources," Journal of Environmental Econ and Management, 30: 1-17.

[18] Wirl, F. (1994), "Pigouvian Taxation of Energy for Flow and Stock Externalities and Strategic, Non-competitive Energy Pricing," Journal of Environmental Econ and Management, 26: 1-18. 


\begin{tabular}{|c|c|c|}
\hline & $\alpha$ & $\alpha^{*}$ \\
\hline \hline Nash & -0.227475584 & -0.160849528 \\
\hline Stackelberg (Home is leader) & -0.200588442 & -0.163091829 \\
\hline Stackelberg (Foreign is leader) & -0.16381011 & -0.11583124 \\
\hline
\end{tabular}

Table 1: $\alpha$ and $\alpha^{*}$ under $S_{0}=0, r=0.1, c=1$ and $b^{2}=0.5$

\begin{tabular}{|c|c|c|}
\hline & $\beta$ & $\beta^{*}$ \\
\hline \hline Nash & $0.227475584 a$ & $0.160849528 a$ \\
\hline Stackelberg (Home is leader) & $0.200588442 a$ & $0.163091829 a$ \\
\hline Stackelberg (Foreign is leader) & $0.16381011 a$ & $0.11583124 a$ \\
\hline
\end{tabular}

Table 2: $\beta$ and $\beta^{*}$ under $S_{0}=0, r=0.1, c=1$ and $b^{2}=0.5$

\begin{tabular}{|c|c|c|c|c|}
\hline & Home & Foreign & ROW & Total \\
\hline \hline Nash & $0.043383237 a^{2}$ & $0.258725708 a^{2}$ & $0.015155801 a^{2}$ & $0.317264746 a^{2}$ \\
\hline Home leader & $0.043757137 a^{2}$ & $0.265989447 a^{2}$ & $0.013616879 a^{2}$ & $0.323363463 a^{2}$ \\
\hline Foreign leader & $0.028604876 a^{2}$ & $0.268337521 a^{2}$ & $0.007859424 a^{2}$ & $0.304801821 a^{2}$ \\
\hline
\end{tabular}

Table 3: Payoffs under $S_{0}=0, r=0.1, c=1$ and $b^{2}=0.5$ 


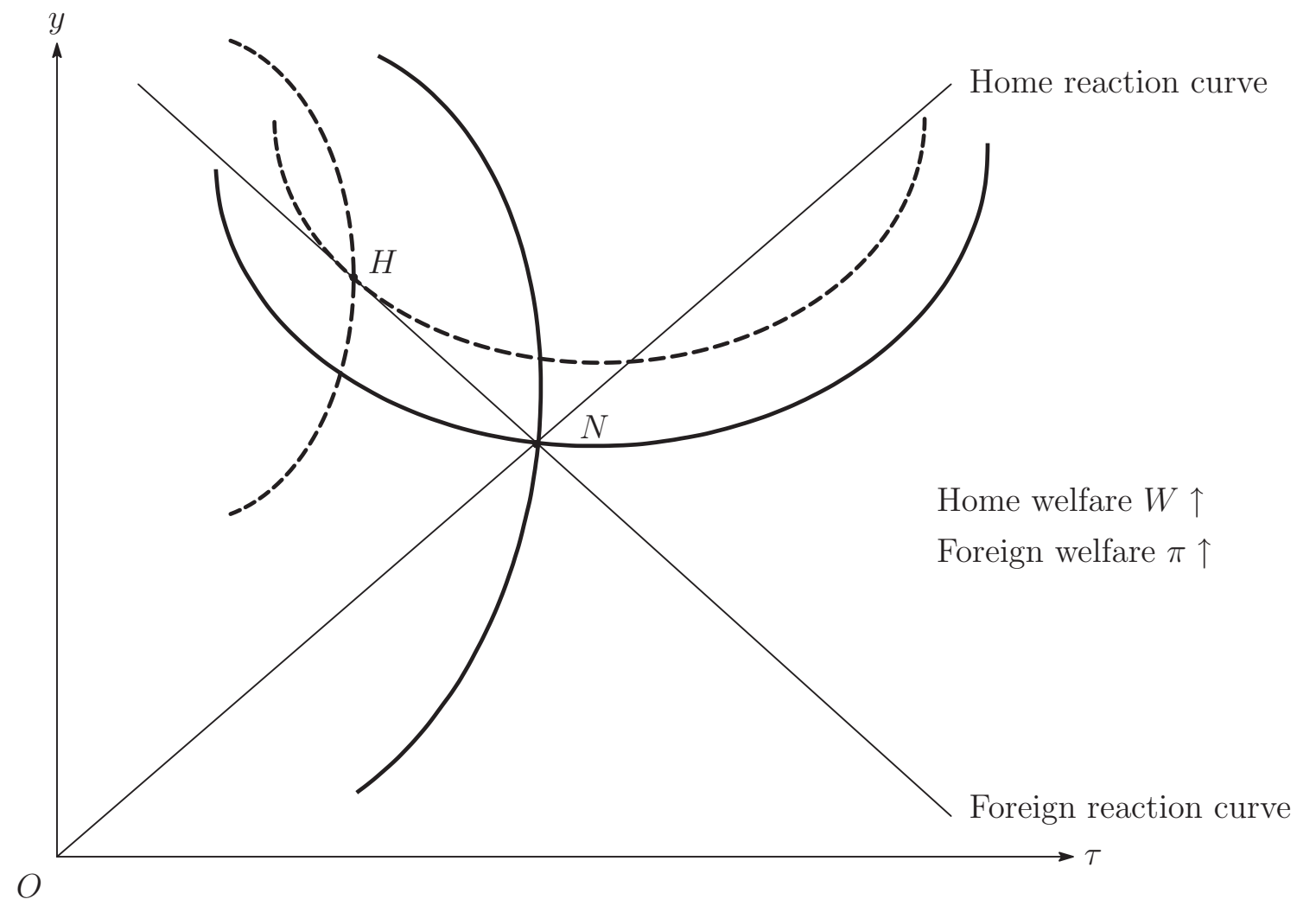

Figure 1: Static Stackelberg equilibrium: Home is a leader 


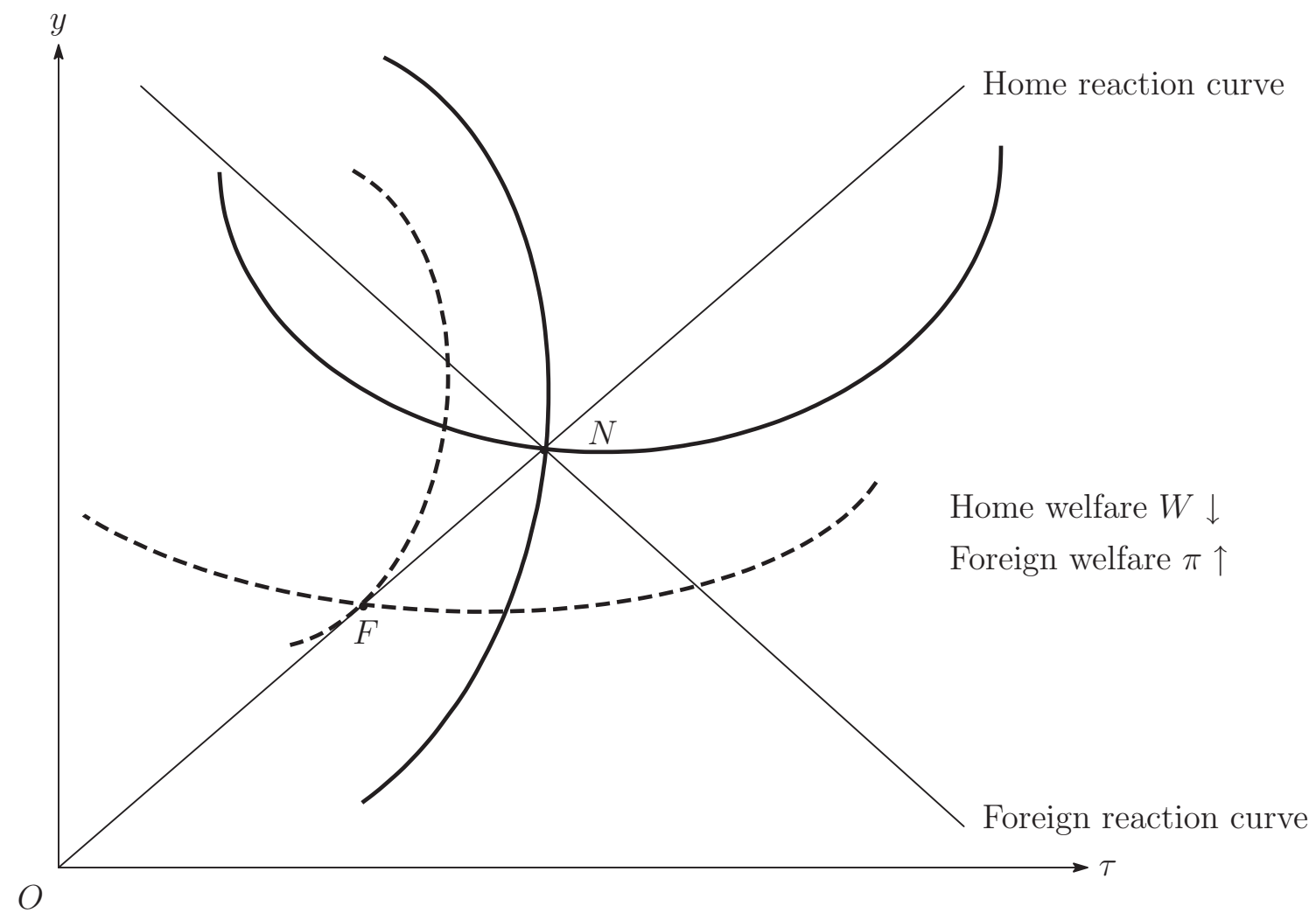

Figure 2: Static Stackelberg equilibrium: Foreign is a leader 


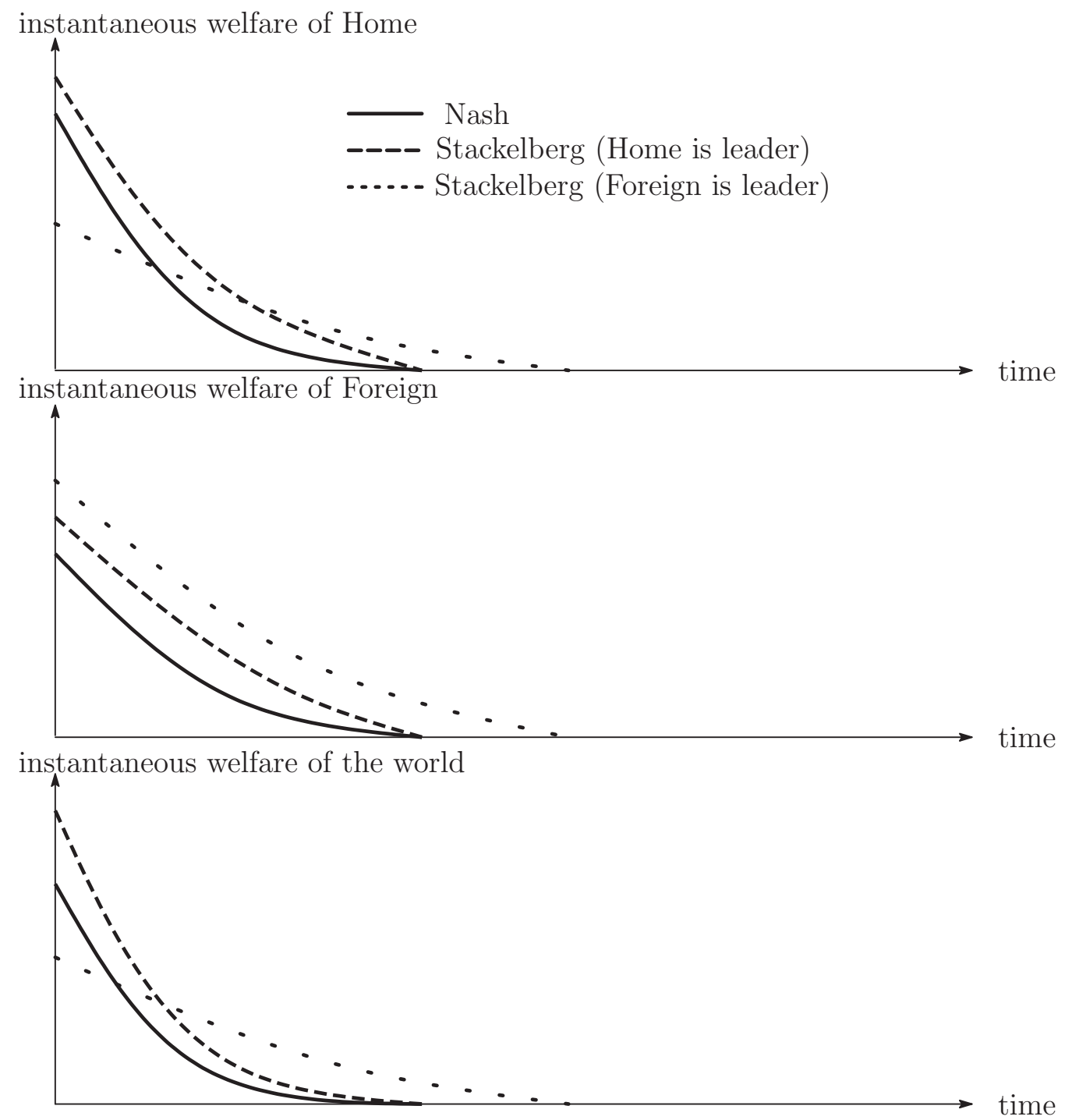

Figure 3: Time paths of welfare 